BMJ Open

Respiratory

Research

\title{
The impact of chronic obstructive pulmonary disease on intensive care unit admission and 30-day mortality in patients undergoing colorectal cancer surgery: a Danish population-based cohort study
}

Anna Maria Platon, Rune Erichsen, Christian Fynbo Christiansen,
Lea Kjær Andersen, Claus Sværke, Jonathan Montomoli, Henrik Toft Sørensen

\section{ABSTRACT}

Erichsen $\mathrm{R}$, Christiansen $\mathrm{CF}$, et al. The impact of chronic obstructive pulmonary disease on intensive care unit admission and 30-day mortality in patients undergoing colorectal cancer surgery: a Danish populationbased cohort study. BMJ Open Resp Res 2014;1: e000036. doi:10.1136/ bmjresp-2014-000036

- Additional material is available. To view please visit the journal (http://dx.doi.org/ 10.1136/bmjresp-2014000036)

Received 28 March 2014 Revised 18 May 2014 Accepted 8 June 2014

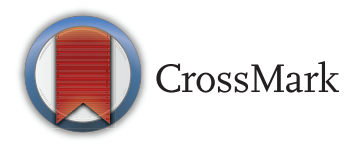

Department of Clinical Epidemiology, Aarhus University Hospital, Aarhus, Denmark

Correspondence to Dr Anna Maria Platon; mariaplaton@mail.com sparse.
Background and purpose: Chronic obstructive pulmonary disease (COPD) may increase the risk of postoperative complications and thus mortality after colorectal cancer (CRC) surgery, but the evidence is

Methods: We conducted this nationwide populationbased cohort study in Denmark, including all patients undergoing CRC surgery in the period 2005-2011, identified through medical databases. We categorised the patients according to the history of COPD.

We assessed the rate of complications within 30 days. We computed 30-day mortality among patients with/without COPD using the Kaplan-Meier method. We used Cox regression to compute HRs for death, controlling for age, gender, type of admission, cancer stage, hospital volume, alcohol-related diseases, obesity and Charlson comorbidity score.

Results: We identified 18302 CRC surgery patients. Of these, $7.9 \%$ had a prior diagnosis of COPD. Among patients with COPD, $16.1 \%$ were admitted postoperatively to the intensive care unit, $1.9 \%$ were treated with mechanical ventilation, and $3.6 \%$ were treated with non-invasive ventilation. In patients without COPD, the corresponding proportions were $9.7 \%, 1.1 \%$ and $1.1 \%$. The reoperation rate was $10.6 \%$ among patients with COPD and $8 \%$ among patients with cancer without COPD. 30-day mortality was $13 \%$ (95\% Cl $11.4 \%$ to $14.9 \%$ ) among patients with COPD and $5.3 \%(95 \% \mathrm{Cl} 5.0 \%$ to $5.7 \%)$ among patients without COPD, corresponding to an adjusted HR of 1.7 (95\% Cl 1.5 to 2.0$)$.

Conclusions: COPD is a strong predictor for intensive care unit admission and mortality after CRC surgery.

\section{INTRODUCTION}

Colorectal cancer (CRC) is a common disease, with a first-time diagnosis occurring at a median age of approximately 70 years. ${ }^{1}{ }^{2}$

\section{KEY MESSAGES}

Surgery in CRC patients with COPD is more frequently associated with complications leading to ICU admission/treatments, and reoperations, compared to CRC patients without COPD.

- COPD is clearly associated with increased mortality especially in patients with colon cancer.

Surgical resection of the tumour has the potential to cure early-stage CRC, either alone or combined with chemotherapy and/or radiation. ${ }^{3}$ Overall, 30-day mortality after CRC resection has been estimated to be approximately $10 \%{ }^{4}$ with higher rates among elderly patients compared to younger patients. ${ }^{5}$

Many patients with CRC have concurrent chronic diseases, including chronic obstructive pulmonary disease (COPD). Evidence suggests that COPD is associated with substantially increased mortality after various types of surgery. ${ }^{4-10}$ Much of this evidence originates from studies of patients undergoing surgery for perforated peptic ulcers, cardiac procedures, hip fractures and abdominal aortic aneurysm repair. ${ }^{6-8} 11$ The studies have mainly included COPD as a covariate in analyses for other purposes like hospital variation in mortality ${ }^{4}$ have combined several types of cancer or lung diseases ${ }^{9} 12$ or focused only on men. ${ }^{10}$ However, evidence of an association between COPD and postoperative outcome after CRC surgery is limited. 41013

A primary reason for increased postoperative mortality among patients with COPD may be respiratory failure, leading to more frequent and longer intensive care unit (ICU) admissions. ${ }^{7} 11$ In addition, patients 
with a high comorbidity burden have in general been found to be at increased risk of surgical complications, leading in turn to a need for reoperation, ${ }^{14}$ but none of the former studies have examined the risk of postoperative admission to the ICU among patients undergoing CRC surgery.

We conducted a nationwide population-based cohort study to investigate the impact of COPD on ICU admissions, ICU treatments (mechanical ventilation, noninvasive ventilation (NIV), dialysis and treatment with inotropes/vasopressors), occurrence of reoperation and 30-day mortality following CRC surgery.

\section{METHODS}

\section{Settings}

This cohort study was conducted in Denmark, a country with 5.5 million inhabitants.

All Danish citizens have equal access to tax-funded medical care, and all CRC surgery is performed in public hospitals.

Since 1968, everyone living in Denmark has been assigned a personal civil registration number (CPR number) by the Danish Civil Registration System (CRS). ${ }^{15}$ The CRS is updated daily and contains information on gender, date of birth and vital status. We used the CPR number to link registries at the individual level.

\section{Patients}

We used the Danish Cancer Registry (DCR) to identify all patients with CRC diagnosed in the period from 1 January 2005 until 31 December 2011. This period was chosen because ICU admissions have been recorded since 2005. The DCR, established in 1943, covers all incident cancer cases in Denmark through notification from hospital departments, specialists and autopsy reports. ${ }^{16}$ DCR data include CPR number, month and year of cancer diagnosis and tumour spread at the time of diagnosis. We classified CRC stages as localised (Dukes' A and B), regional (Dukes' C), metastasised (Dukes' D) or unknown (see e-appendix 1).

We linked the patients with CRC to the Danish National Registry of Patients (DNRP), in order to identify date of CRC surgery. The DNRP, a nationwide registry established in 1977, contains records on $99.4 \%$ of all discharges from Danish hospitals. ${ }^{17}$ Emergency room and outpatient clinic visits have been included since 1995 and ICU admissions, including information on use of mechanical ventilation and other ICU treatments, since 2005 .

The DNRP includes data on CPR number, hospital, department, discharge diagnoses and surgical and diagnostic procedures. Diagnoses were coded according to the International Classification of Diseases, 8th revision (ICD-8) until 1993 and 10th revision (ICD-10) thereafter. Our study cohort consisted of patients who underwent CRC surgery (see e-appendix 1 for surgical procedure codes). We categorised CRC surgery as open surgery, laparoscopic resection or other surgery; in addition, we investigated colon and rectal cancer surgery separately. We also categorised type of admission as acute or elective because acute surgery has been shown to be associated with increased mortality. ${ }^{4}$ Furthermore, we divided hospitals according to volume: low volume (less than 500 CRC surgeries in the study period) and high volume (more than 500 CRC surgeries in the study period).

\section{Patients with COPD}

Within the cohort of CRC surgery patients, we searched the DNRP for any inpatient COPD diagnosis since 1977. In addition, we identified and included patients diagnosed with COPD in outpatient specialist clinics and emergency rooms since 1995 (ICD codes are provided in e-appendix 1).

\section{Main outcome measures}

Admission to the ICU, ICU treatments, reoperation and death

We obtained data from the DNRP on ICU admissions, ${ }^{18}$ use of mechanical ventilation, treatment with NIV, dialysis, inotropic treatment and reoperations within 30 days following surgery as a marker of surgical complications. ${ }^{19}$ To avoid including prophylactic ICU admissions as a marker of surgical complications, we only included ICU admission occurring at least 1 day after surgery. In addition, we divided the reason for reoperation according to the procedure code into five groups: infection, bleeding, wound rupture, anastomosis leakage and other reasons (procedure codes are provided in eappendix 1). To investigate 30-day mortality, CRS data were used to follow patients from date of CRC surgery until death, emigration, 30 days postoperatively or the end of the study period, whichever came first.

\section{Comorbidities}

We used Charlson Comorbidity Index (CCI) scores to assess comorbidity levels in the study cohort. ${ }^{20}$ The CCI score is computed as the sum of points (between 1 and 6) assigned to each of the 19 diseases included in the index (see e-appendix 1). ${ }^{20}$ Information on comorbid diseases was obtained from the DNRP, including all inpatient and outpatient diagnoses within 5 years prior to date of CRC surgery. Patients were classified into three groups according to their CCI score: 0 points ('low comorbidity level'); 1-2 points ('moderate comorbidity level'); and 3 or more points ('severe comorbidity level'). We excluded COPD and CRC from the CCI as they represent the exposure and the patient population under study. In addition to the CCI score, our analyses included data on alcohol-related diseases and obesity from the DNRP (see e-appendix 1).

\section{Statistical analyses}

We calculated frequencies of covariates (including categories of demographic characteristics, CCI scores, types of admission (elective or acute), types of surgery, hospital volume and cancer stage) according to the presence or absence of COPD. We computed the rates of patients 
with CRC who were admitted to the ICU 1-30 days after surgery, and received mechanical ventilation, NIV, dialysis, inotropes/vasopressors or underwent reoperation within 30 days after surgery. In a sensitivity analysis, we also computed the rate of ICU admission 0-30 days after surgery. We used Jeffrey's method to compute 95\% CIs for the rates. ${ }^{21}$ We estimated and plotted 30-day mortality according to presence/or absence of COPD for all CRC surgery patients and for those with colon and rectal cancer separately, using the Kaplan-Meier method. We used a Cox regression model to compute HRs with $95 \%$ CIs as a measure for the relative risk of death, in order to compare mortality rates among patients with CRC with and without COPD. We adjusted for the following potential confounders: age, gender, type of admission (elective/acute), cancer stage, hospital volume, alcohol-related diseases (as a measure for heavy alcohol consumption), obesity and CCI score. Patients with CRC without COPD constituted the comparison group. In order to examine any potential differences in the influence of COPD within particular subgroups, we repeated the regression analyses stratified by age, gender, presence/absence of a comorbid condition according to the Charlson comorbidity score, admission type (elective/acute), surgery type, hospital volume and CRC stage.

All statistical analyses were performed using STATA software (V.10.0 StataCorp LP, College Station, Texas, USA).

All data were obtained from Danish registries, which are generally available to researchers, and their use does not require ethical approval or informed consent.

\section{RESULTS}

\section{Descriptive data}

We identified 18302 CRC surgery patients, of whom $1449(7.9 \%)$ had a COPD diagnosis. The proportion of patients with COPD was slightly higher among patients with colon cancer (8.3\% of 12053 patients with colon cancer) compared to patients with rectal cancer $(7.1 \%$ of 6249 patients with rectal cancer).

Patients with CRC with COPD were older and had a higher comorbidity level than patients with CRC without COPD. Gender, admission type (elective/acute), surgery type and CRC stage at time of diagnosis were very similar in patients with and without COPD (table 1).

\section{ICU admission, ICU treatments and reoperation within 30 days after surgery}

Among patients with CRC with COPD, $16.1 \%$ (95\% CI $14.3 \%$ to $18.1 \%$ ) were admitted to the ICU $1-30$ days after surgery, compared with $9.7 \%$ (95\% CI $9.3 \%$ to $10.2 \%$ ) of patients without COPD (table 2). In the sensitivity analysis including days 0-30 after surgery, we found an ICU admission rate of $29.0 \%$ (95\% CI $26.7 \%$ to $31.4 \%$ ) among patients with COPD and $17.6 \%$ (95\% CI $17.0 \%$ to $18.2 \%$ ) among patients without COPD (e-appendix 2).

Patients with CRC with COPD also received mechanical ventilation treatment more frequently $(1.9 \%$; $95 \%$
CI $1.3 \%$ to $2.8 \%)$ than patients without COPD (1.1\%; 95\% CI $1.0 \%$ to $1.3 \%$ ) and more frequently received treatment with NIV $(3.6 \%$; $95 \%$ CI $2.7 \%$ to $4.7 \%$ vs $1.1 \%$; $95 \%$ CI $0.9 \%$ to $1.2 \%$; table 2 ).

More patients with CRC with COPD than those without COPD underwent reoperation $(10.6 \%$ (95\% CI $9.0 \%$ to $12.3 \%$ ) vs $8.0 \%$ (95\% CI $7.6 \%$ to $8.4 \%$ ), particularly due to wound ruptures and bleeding (tables 2 and 3). Patients with COPD more frequently received inotropes/ vasopressors than patients without COPD (table 2). In addition, ICU admissions, ICU treatments and reoperations were generally more frequent in the acute than in the elective setting, both among patients with CRC with and without COPD (e-appendix 2).

The results were similar when colon cancer and rectal cancer were considered separately (table 2 ).

In an analysis by year of CRC surgery, we found that the frequency of ICU admission declined for CRC surgery overall from $41.6 \%$ in 2005 to $25.8 \%$ in 2011 (Results in e-appendix 2). Among patients with CRC without COPD, 24\% were admitted to the ICU in 2005 and $12.8 \%$ were admitted in 2011 . Thus, while the frequency of ICU admission declined over time among patients with CRC overall, the frequency continued to be highest among patients with CRC with COPD.

In contrast, we found that the rate of patients treated with mechanical ventilation increased from $1.2 \%$ in 2005 to $2 \%$ in 2010 among patients with CRC with COPD. In patients with CRC without COPD, the frequency increased from $0.8 \%$ to $1.2 \%$. The frequency of reoperation was stable throughout the study period, except for a higher frequency in 2005 (e-appendix 2).

\section{Mortality}

Thirty-day mortality after CRC surgery was $13.0 \%$ (95\% CI $11.4 \%$ to $14.9 \%$ ) among patients with CRC with COPD and $5.3 \%$ (95\% CI 5\% to 5.7\%) among patients with CRC without COPD, corresponding to an adjusted HR of 1.7 (95\% CI 1.5 to 2.0). Mortality in patients with CRC with COPD started to diverge from that in patients with CRC without COPD approximately 3 days after surgery (figure 1 ).

Thirty-day mortality was $14.8 \%$ (95\% CI $12.8 \%$ to $17.2 \%)$ in patients with colon cancer with COPD and $6.2 \%(95 \%$ CI $5.8 \%$ to $6.7 \%)$ in patients with colon cancer without COPD, corresponding to an adjusted HR of 1.8 (95\% CI $1.5 \%$ to $2.1 \%)$.

Thirty-day mortality was $9.0 \% \quad(95 \%$ CI $6.7 \%$ to $12.1 \%$ ) in patients with rectal cancer with COPD and $3.7 \%$ (95\% CI $3.3 \%$ to $4.2 \%)$ in patients with rectal cancer without COPD. The adjusted HR was 1.6 (95\% CI $1.1 \%$ to $2.2 \%$; table 4 ).

\section{Stratified analyses}

Stratified analyses showed that COPD had a particularly strong impact on 30-day mortality among patients less than 70 years of age $(\mathrm{HR}=2.0 ; 95 \%$ CI $1.3 \%$ to $3.0 \%)$, 
Table 1 Characteristics of patients undergoing colon and rectal cancer surgery by presence/absence of a previous diagnosis of COPD, Denmark, 2005-2011

\begin{tabular}{|c|c|c|c|c|c|c|c|c|}
\hline & \multicolumn{4}{|c|}{ Colon cancer } & \multicolumn{4}{|c|}{ Rectal cancer } \\
\hline & COPD & Per cent & $\begin{array}{l}\text { No } \\
\text { COPD }\end{array}$ & Per cent & COPD & Per cent & $\begin{array}{l}\text { No } \\
\text { COPD }\end{array}$ & Per cent \\
\hline Total & 1006 & 100 & 11047 & 100 & 443 & 100 & 5806 & 100 \\
\hline \multicolumn{9}{|l|}{ Age group (years) } \\
\hline $0-59$ & 40 & 4.0 & 1784 & 16.2 & 32 & 7.2 & 1280 & 22.0 \\
\hline $60-69$ & 178 & 17.7 & 3090 & 28.0 & 92 & 20.8 & 1934 & 33.3 \\
\hline $70-79$ & 406 & 40.3 & 3504 & 31.7 & 202 & 45.6 & 1654 & 28.5 \\
\hline $80+$ & 382 & 38.0 & 2669 & 24.1 & 117 & 26.4 & 938 & 16.2 \\
\hline \multicolumn{9}{|l|}{ Gender } \\
\hline Female & 512 & 50.9 & 5604 & 50.7 & 173 & 39.1 & 2232 & 38.4 \\
\hline Male & 494 & 49.1 & 5443 & 49.3 & 270 & 60.9 & 3574 & 61.6 \\
\hline \multicolumn{9}{|l|}{ Charlson score } \\
\hline 0 & 572 & 56.9 & 8340 & 75.5 & 272 & 61.4 & 4625 & 79.7 \\
\hline $1-2$ & 335 & 33.3 & 2141 & 19.4 & 125 & 28.2 & 867 & 14.9 \\
\hline$>3$ & 99 & 9.8 & 566 & 5.1 & 46 & 10.4 & 314 & 5.4 \\
\hline \multicolumn{9}{|l|}{ Charlson score } \\
\hline Myocardial infarction & 55 & 5.5 & 265 & 2.4 & 28 & 6.3 & 120 & 2.1 \\
\hline Congestive heart failure & 131 & 13.0 & 346 & 3.1 & 43 & 9.7 & 133 & 2.3 \\
\hline Peripheral vascular disease & 66 & 6.6 & 358 & 3.2 & 33 & 7.5 & 134 & 2.3 \\
\hline Cerebrovascular disease & 104 & 10.3 & 701 & 6.4 & 43 & 9.7 & 288 & 5.0 \\
\hline Dementia & 13 & 1.3 & 96 & 0.9 & 6 & 1.4 & 51 & 0.9 \\
\hline Connective tissue disease & 42 & 4.2 & 225 & 2.0 & 13 & 2.9 & 68 & 1.2 \\
\hline Ulcer disease & 46 & 4.6 & 351 & 3.2 & 15 & 3.4 & 55 & 1.0 \\
\hline Mild liver disease & 9 & 0.9 & 51 & 0.5 & 6 & 1.3 & 28 & 0.5 \\
\hline Diabetes I and II & 122 & 12.1 & 686 & 6.2 & 37 & 8.3 & 298 & 5.1 \\
\hline Hemiplegia & 3 & 0.3 & 10 & 0.1 & 1 & 0.2 & 2 & 0.1 \\
\hline Moderate/severe renal disease & 35 & 3.5 & 135 & 1.2 & 7 & 1.6 & 50 & 0.9 \\
\hline Diabetes with complication & 51 & 5.1 & 304 & 2.8 & 18 & 4.1 & 131 & 2.3 \\
\hline Any tumour (except colon and rectal) & 15 & 1.5 & 93 & 0.8 & 3 & 0.7 & 45 & 0.8 \\
\hline Leukaemia & 0 & 0.0 & 5 & 0.1 & 1 & 0.2 & 2 & 0.03 \\
\hline Lymphoma & 0 & 0.0 & 5 & 0.1 & 0 & 0.0 & 1 & 0.02 \\
\hline Moderate/severe liver disease & 3 & 0.3 & 11 & 0.1 & 1 & 0.2 & 7 & 0.1 \\
\hline $\begin{array}{l}\text { Metastatic solid tumour (except } \\
\text { colon and rectal) }\end{array}$ & 14 & 1.4 & 226 & 2.0 & 16 & 3.6 & 188 & 96.8 \\
\hline AIDS & 1 & 0.1 & 3 & 0.03 & 0 & 0.0 & 2 & 0.03 \\
\hline \multicolumn{9}{|l|}{ Type of admission } \\
\hline Elective & 683 & 67.9 & 7799 & 70.6 & 379 & 13.5 & 5202 & 9.9 \\
\hline Acute & 322 & 32.0 & 3221 & 29.2 & 60 & 85.6 & 572 & 89.6 \\
\hline Unknown & 1 & 0.1 & 27 & 0.2 & 4 & 0.9 & 32 & 0.5 \\
\hline \multicolumn{9}{|l|}{ Type of surgery } \\
\hline Open & 636 & 63.2 & 6685 & 60.5 & 224 & 50.6 & 2838 & 48.9 \\
\hline Laparoscopic & 257 & 25.6 & 3236 & 29.3 & 72 & 16.2 & 1160 & 20.0 \\
\hline Other & 113 & 11.2 & 1126 & 10.2 & 147 & 33.2 & 1807 & 31.1 \\
\hline \multicolumn{9}{|l|}{ Cancer stage } \\
\hline Localised & 450 & 44.7 & 4291 & 38.8 & 179 & 40.4 & 2048 & 35.3 \\
\hline Regional & 202 & 20.1 & 2928 & 26.5 & 113 & 25.5 & 2033 & 35.0 \\
\hline Metastasised & 214 & 21.3 & 2418 & 21.9 & 70 & 15.8 & 904 & 15.6 \\
\hline Unknown & 140 & 13.9 & 1410 & 12.8 & 81 & 18.3 & 821 & 14.1 \\
\hline
\end{tabular}

among men ( $\mathrm{HR}=1.9 ; 95 \%$ CI $1.6 \%$ to $2.4 \%)$, among patients undergoing elective surgery $(\mathrm{HR}=2.2 ; 95 \%$ CI $1.8 \%$ to $2.8 \%$ ), among patients undergoing surgery in a low volume hospital (HR=2.1; 95\% CI $1.4 \%$ to $3.0 \%$ ) and among patients undergoing laparoscopic surgery $(\mathrm{HR}=2.9 ; 95 \%$ CI $1.8 \%$ to $4.7 \%$; table 5$)$.

\section{DISCUSSION}

Key messages

- Surgery in patients with CRC with COPD is more frequently associated with complications leading to ICU admission/treatments, and reoperations, compared to patients with CRC without COPD. 
Table 2 Postoperative treatment within 30 days after all colon and rectal cancer surgery by presence/absence of a previous diagnosis of COPD, Denmark, 2005-2011

\begin{tabular}{|c|c|c|c|c|c|c|}
\hline & $\begin{array}{l}\text { ICU } \\
\text { admission (\%) }\end{array}$ & NIV (\%) & $\begin{array}{l}\text { Mechanical } \\
\text { Ventilation (\%) }\end{array}$ & Reopera-tion (\%) & Dialysis (\%) & $\begin{array}{l}\text { Treatment with } \\
\text { inotropes/ } \\
\text { vasopressors (\%) }\end{array}$ \\
\hline \multicolumn{7}{|c|}{ Colorectal cancer } \\
\hline COPD & 16.1 (14.3 to 18.1$)$ & 3.6 (2.7 to 4.7 ) & 1.9 (1.3 to 2.8$)$ & 10.6 (9.0 to 12.3$)$ & 10.9 (9.3 to 12.6$)$ & 11.8 (10.2 to 13.6$)$ \\
\hline No COPD & 9.7 (9.3 to 10.2$)$ & 1.1 (0.9 to 1.2$)$ & 1.1 (1.0 to 1.3 ) & $8.0(7.6$ to 8.4$)$ & $5.4(5.1$ to 5.8$)$ & $6.2(5.8$ to 6.5$)$ \\
\hline \multicolumn{7}{|l|}{ Colon cancer } \\
\hline COPD & 17.0 (14.7 to 19.5$)$ & $3.8(2.7$ to 5.1$)$ & 2.2 (1.4 to 3.3 ) & $11.3(9.4$ to 13.5$)$ & $12.5(10.5$ to 14.7$)$ & 12.7 (10.7 to 14.9$)$ \\
\hline No COPD & 9.7 (9.2 to 10.3$)$ & $1.2(1.0$ to 1.4$)$ & $1.2(1.0$ to 1.4$)$ & 7.8 (7.3 to 8.4$)$ & $5.9(5.5$ to 6.4$)$ & $6.4(6.0$ to 6.9$)$ \\
\hline \multicolumn{7}{|l|}{ Rectal cancer } \\
\hline COPD & $14.2(11.1$ to 17.8$)$ & $3.2(1.7$ to 5.2$)$ & $1.4(0.5$ to 2.3$)$ & 8.8 (6.3 to 11.8$)$ & 7.2 (5.0 to 10.0$)$ & 9.7 (7.1 to 12.9$)$ \\
\hline No COPD & 9.6 (9.0 to 10.4$)$ & $0.9(0.6$ to 1.1$)$ & $1.0(0.8$ to 1.3$)$ & $8.3(7.6$ to 9.0$)$ & 4.5 (4.0 to 5.1$)$ & 5.7 (5.1 to 6.3$)$ \\
\hline
\end{tabular}

- COPD is clearly associated with increased mortality, especially in patients with colon cancer.

\section{Other studies}

To the best of our knowledge, this is the first study to focus specifically on the impact of COPD on postoperative mortality and, in particular, intensive care treatment among patients with CRC. Nonetheless, our mortality results are in accord with those of a study by Osler et al who investigated hospital differences in mortality after CRC surgery. ${ }^{4}$ In that study, presence of COPD was associated with a $71 \%$ increase in 30-day mortality compared to CRC patients without COPD. Studies investigating the impact of COPD on mortality after other types of surgery have also demonstrated an association. ${ }^{6-8}{ }^{22}$ For example, Ried $e t a l^{7}$ found that $6.1 \%$ of patients with COPD died within 30 days of cardiac surgery, compared to $0.8 \%$ of patients without COPD. Moreover, a study by Christensen et at reported a 30-day mortality of $44 \%$ after surgery for peptic ulcer among patients with COPD and 25\% among patients without COPD, corresponding to a $50 \%$ increased mortality in patients with COPD after adjustment for confounders.

\section{Potential mechanisms}

Several physiological mechanisms may explain our findings. Previous studies have shown that patients with COPD suffer more often from postoperative respiratory complications, such as pneumonia, than patients without COPD. ${ }^{13} 22$ This is supported by our findings of an association between COPD and an increased rate of ICU admission, mechanical ventilation and NIV. Nonetheless, the rates of mechanical ventilation and NIV among patients with COPD remained low, suggesting that a substantial proportion of ICU admissions were related to complications not requiring ventilation support. Furthermore, the higher rate of ICU admissions among patients with CRC with COPD, compared to patients without COPD, could possibly be explained by the fact that some hospitals previously routinely admitted patients with COPD to ICU after CRC surgery. Most hospitals have abandoned this practice, as indicated in our study, which found the most pronounced decline in the number of ICU admissions from 2005 to 2011 among patients with COPD.

Patients with severe COPD who experience exacerbations are usually treated with glucocorticoids, which slow wound healing. ${ }^{23}$ This could account for some postoperative complications experienced by patients with COPD.

Although patients with COPD are less likely to receive laparoscopic surgery, the impact of COPD on mortality was higher in those who had this type of surgery. This increased mortality impact could be due to perioperative hypoventilation when the pressure in the abdomen is increased during laparoscopic surgery, especially since patients with COPD already have decreased lung capacity.

We observed a relatively lower impact of COPD on mortality in acute patients than in elective patients, which may be explained by the higher absolute mortality risk in acute patients even without COPD.

Table 3 Postoperative reoperations within 30 days after all colorectal cancer surgery by presence/absence of a previous diagnosis of chronic obstructive pulmonary disease (COPD), Denmark, 2005-2011

\begin{tabular}{llllll}
\hline & $\begin{array}{l}\text { Wound } \\
\text { rupture (\%) }\end{array}$ & $\begin{array}{l}\text { Superficial/deep } \\
\text { infection (\%) }\end{array}$ & $\begin{array}{l}\text { Superficial/deep } \\
\text { bleeding (\%) }\end{array}$ & $\begin{array}{l}\text { Anastomosis } \\
\text { leakage (\%) }\end{array}$ & $\begin{array}{l}\text { Other reason for } \\
\text { reoperation (\%) }\end{array}$ \\
\hline $\begin{array}{lllll}\text { COPD } \\
\text { Yes }\end{array}$ & $4.1(3.2$ to 5.3$)$ & $0.9(0.5$ to 1.5$)$ & $2.1(1.4$ to 2.9$)$ & $3.5(2.6$ to 4.6$)$ & $1.0(0.5$ to 1.6$)$ \\
No & $2.0(1.8$ to 2.2$)$ & $1.3(1.1$ to 1.5$)$ & $0.8(0.7$ to 1.0$)$ & $3.1(2.9$ to 3.4$)$ & $0.7(0.6$ to 0.9$)$ \\
\hline Numbers in parentheses are $95 \% \mathrm{Cl}$ &
\end{tabular}




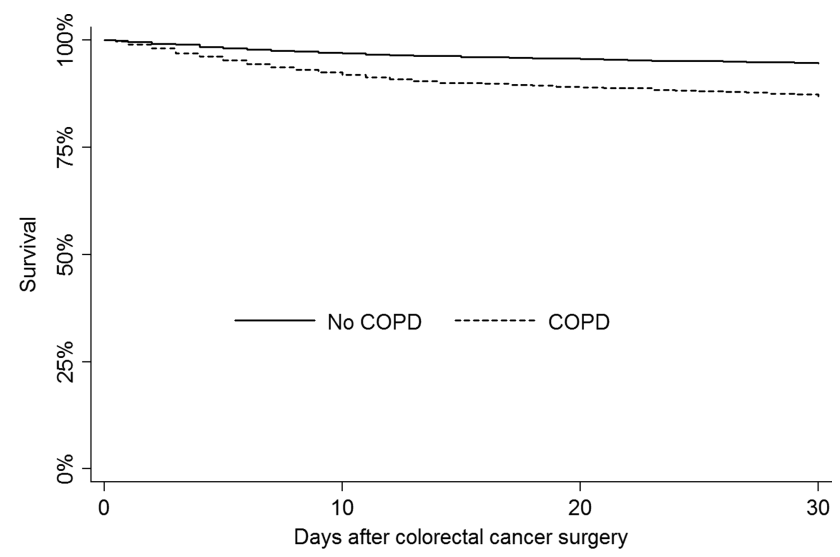

Figure 1 Kaplan-Meier 30-day survival curves for patients with colorectal cancer with and without chronic obstructive pulmonary disease (COPD).

A previous study found that patients with CRC with COPD are diagnosed and treated earlier than patients without COPD, so delay in diagnosis and treatment cannot therefore explain the poor prognosis. ${ }^{24}$

\section{Limitations}

In this nationwide population-based study conducted in a homogeneous healthcare system, we had complete DCR data and complete follow-up for death, allowing almost no risk of selection bias. ${ }^{25}$ Nonetheless, COPD may be underreported in the DNRP, in which case we have included some true patients with COPD in the comparison cohort. Such misclassification would have caused us to conservatively bias the relative risk estimates. In the Danish study by Osler et al, however, where COPD was defined using both hospitalisations and prescriptions, the COPD prevalence was $11.2 \%$, which is in accord with our findings. ${ }^{4}$ These findings may imply that under-reporting of COPD is not a major problem in our study. Furthermore, the coding of COPD and ICU admissions and treatments in the DNRP has been demonstrated to have a high-positive predictive value. ${ }^{26}{ }^{27}$ However, the DNRP does not include detailed clinical data on severity of COPD, and we were therefore unable to evaluate any influence of COPD severity.

We controlled for several important sources of confounding, such as obesity, alcohol-related diseases and other comorbidities. The positive predictive value of the DNRP coding of all diseases included in the CCI is known to be high, ${ }^{28}$ but the index includes limited information on the severity of comorbidity. Despite this, the CCI performs well in colorectal cancer surgery patients. ${ }^{29}$ However, we cannot entirely rule out unmeasured confounding from smoking and incomplete measurement of comorbidity including obesity and alcohol-related diseases.

Although it is very likely that deaths occurring 30 days or less after CRC surgery are caused by complications, information on causes of death may have provided further insight into the mechanisms leading to increased mortality among patients with COPD. Unfortunately, we had no information on causes of death. 
Table 5 Crude and adjusted HRs for death after colorectal cancer (CRC) surgery, comparing patients with chronic obstructive pulmonary disease (COPD) to those without

\begin{tabular}{|c|c|c|c|}
\hline & \multicolumn{3}{|l|}{ Colorectal cancer } \\
\hline & \multicolumn{2}{|l|}{ COPD } & \multirow{2}{*}{$\begin{array}{l}\text { No COPD } \\
\text { Reference }\end{array}$} \\
\hline & Crude HR (95\% CI) & Adjusted HR (95\% Cl) & \\
\hline \multicolumn{4}{|c|}{ Stratified by } \\
\hline \multicolumn{4}{|c|}{ Age group (years) } \\
\hline $0-69$ & 2.5 (1.5 to 4.1$)$ & 2.0 (1.3 to 3.0$)$ & 1.0 \\
\hline $70+$ & 1.9 (1.6 to 2.3$)$ & 1.6 (1.4 to 2.0$)$ & 1.0 \\
\hline \multicolumn{4}{|l|}{ Gender } \\
\hline Male & 2.9 (2.4 to 3.6$)$ & 1.9 (1.6 to 2.4$)$ & 1.0 \\
\hline Female & 2.1 (1.7 to 2.7$)$ & 1.5 (1.2 to 1.9$)$ & 1.0 \\
\hline \multicolumn{4}{|l|}{ Charlson score } \\
\hline 0 & 2.7 (2.2 to 3.4$)$ & 2.1 (1.7 to 2.6$)$ & 1.0 \\
\hline $1-2$ & 1.7 (1.3 to 2.3$)$ & 1.5 (1.1 to 1.9$)$ & 1.0 \\
\hline $3+$ & 1.7 (1.1 to 2.6$)$ & 1.5 (1.0 to 2.3$)$ & 1.0 \\
\hline \multicolumn{4}{|c|}{ Type of admission } \\
\hline Elective & 3.3 (2.7 to 4.1$)$ & 2.2 (1.8 to 2.8$)$ & 1.0 \\
\hline Acute & 1.8 (1.4 to 2.2$)$ & $1.4(1.1$ to 1.7$)$ & 1.0 \\
\hline \multicolumn{4}{|l|}{ Hospital volume } \\
\hline Low (0-500) & 2.8 (2.0 to 4.0$)$ & 2.1 (1.4 to 3.0$)$ & 1.0 \\
\hline High $(>500)$ & 2.5 (2.1 to 3.0$)$ & 1.7 (1.4 to 2.0$)$ & 1.0 \\
\hline \multicolumn{4}{|l|}{ Type of Surgery } \\
\hline Open & 2.8 (2.3 to 3.5$)$ & 2.0 (1.6 to 2.4$)$ & 1.0 \\
\hline Laparoscopic & 4.4 (2.8 to 7.0$)$ & 2.9 (1.8 to 4.7$)$ & 1.0 \\
\hline Other & 1.4 (1.0 to 2.0$)$ & $1.0(0.7$ to 1.5$)$ & 1.0 \\
\hline \multicolumn{4}{|l|}{ CRC stage } \\
\hline Localised & 2.9 (2.2 to 3.8$)$ & 1.9 (1.4 to 2.5$)$ & 1.0 \\
\hline Regional & 3.4 (2.3 to 5.0$)$ & 2.1 (1.4 to 3.0$)$ & 1.0 \\
\hline Metastasised & 2.4 (1.8 to 3.2$)$ & 1.7 (1.2 to 2.2$)$ & 1.0 \\
\hline Unknown & 1.7 (1.2 to 2.5$)$ & 1.4 (0.9 to 2.0$)$ & 1.0 \\
\hline
\end{tabular}

Finally and as mentioned above, rates of ICU admissions among patients with COPD may reflect clinical practice of routine 'prophylactic' admission rather than ICU admissions as a marker of postoperative complications; however, we addressed this by excluding ICU admission on the day of surgery. By excluding patients admitted to the ICU on the first postoperative day, we may also have excluded some patients with COPD with immediate surgical complications (eg, patients not extubated in the operating room, but transferred to the ICU due to perioperative respiratory complications). Sensitivity analysis aimed to address this issue.

Our findings of a substantial impact of COPD on postoperative morbidity and mortality after CRC surgery underscore the need for close postoperative surveillance of patients with CRC with COPD.

In conclusion, we found an increased rate of ICU admission, mechanical ventilation, NIV and reoperation after CRC surgery in patients with COPD, compared with patients with CRC without COPD. In addition, COPD was associated with increased 30-day mortality after CRC surgery.

Contributors HTS, CFC, RE and AMP conceived the study idea and designed the study. LKA and CS collected the data. AMP analysed the data with help from CS, RE and CFC. All authors interpreted the findings. AMP reviewed the literature together with RE and CFC. AMP wrote the first draft, and all authors critically reviewed and edited the manuscript and approved the final version.

Funding The study received support from the Regional Clinical Epidemiological Monitoring Initiative for the Central Danish Region and North Denmark region, and the Clinical Institute, Aarhus University. The sponsors had no influence on the study design, the collection and analysis, the interpretation of data, the writing of the article or the decision to submit it for publication.

Competing interests None.

Provenance and peer review Not commissioned; externally peer reviewed.

Data sharing statement No additional data are available.

Open Access This is an Open Access article distributed in accordance with the Creative Commons Attribution Non Commercial (CC BY-NC 4.0) license, which permits others to distribute, remix, adapt, build upon this work noncommercially, and license their derivative works on different terms, provided the original work is properly cited and the use is non-commercial. See: http:// creativecommons.org/licenses/by-nc/4.0/

\section{REFERENCES}

1. Jemal A, Bray F, Center MM, et al. Global cancer statistics. $C A$ Cancer J Clin 2011;61:69-90.

2. Marusch F, Koch A, Schmidt U, et al. Impact of age on the short-term postoperative outcome of patients undergoing surgery for colorectal carcinoma. Int J Colorectal Dis 2002;17:177-84.

3. Wilkes G, Hartshorn K. Clinical update: colon, rectal, and anal cancers. Semin Oncol Nurs 2012;28:e1-22.

4. Osler M, Iversen LH, Borglykke A, et al. Hospital variation in 30-day mortality after colorectal cancer surgery in Denmark: the contribution of hospital volume and patient characteristics. Ann Surg 2011;253:733-8. 
5. Schiffmann L, Ozcan S, Schwarz F, et al. Colorectal cancer in the elderly - surgical treatment and long-term survival. Int $J$ Colorectal Dis 2008;23:601-10.

6. Christensen S, Thomsen RW, Tørring ML, et al. Impact of COPD on outcome among patients with complicated peptic ulcer. Chest 2008:133:1360-6.

7. Ried $M$, Unger $P$, Puehler $T$, et al. Mild-to-moderate COPD as a risk factor for increased 30-day mortality in cardiac surgery. Thorac Cardiovasc Surg 2010;58:387-91.

8. De Luise C, Brimacombe M, Pedersen L, et al. Chronic obstructive pulmonary disease and mortality following hip fracture: a population-based cohort study. Eur J Epidemiol 2008;23:115-22.

9. Janssen-Heijnen MLG, Maas HAAM, Houterman S, et al. Comorbidity in older surgical cancer patients: influence on patient care and outcome. Eur J Cancer 2007;43:2179-93.

10. Davila JA, Rabeneck L, Berger DH, et al. Postoperative 30-day mortality following surgical resection for colorectal cancer in veterans: changes in the right direction. Dig Dis Sci 2005;50:1722-8.

11. Axelrod DA, Henke PK, Wakefield TW, et al. Impact of chronic obstructive pulmonary disease on elective and emergency abdominal aortic aneurysm repair. J Vasc Surg 2001;33:72-6.

12. Brewster DH, Clark DI, Stockton DL, et al. Characteristics of patients dying within 30 days of diagnosis of breast or colorectal cancer in Scotland, 2003-2007. Br J Cancer 2011;104:60-7.

13. Lemmens VEPP, Janssen-Heijnen MLG, Houterman S, et al. Which comorbid conditions predict complications after surgery for colorectal cancer? World J Surg 2007;31:192-9.

14. Zingmond $\mathrm{D}$, Maggard $\mathrm{M}, \mathrm{O}$ 'Connell $\mathrm{J}$, et al. What predicts serious complications in colorectal cancer resection? Am Surg 2003;69:969-74.

15. Pedersen CB, Gøtzsche H, Møller JØ, et al. The Danish Civil Registration System. A cohort of eight million persons. Dan Med Bull 2006;53:441-9.

16. Gjerstorff ML. The Danish Cancer Registry. Scand J Public Health 2011;39:42-5.

17. Lynge E, Sandegaard JL, Rebolj M. The Danish National Patient Register. Scand J Public Health 2011;39:30-3.

18. Christiansen CF, Christensen $\mathrm{S}$, Johansen MB, et al. The impact of pre-admission morbidity level on 3-year mortality after intensive care: a Danish cohort study. Acta Anaesthesiol Scand 2011;55:962-70.

19. Van Westreenen HL, IJpma FF, Wevers KP, et al. Reoperation after colorectal surgery is an independent predictor of the 1-year mortality rate. Dis Colon Rectum 2011;54:1438-42.

20. Charlson ME, Pompei P, Ales KA, et al. A new method of classifying prognostic comorbidity in longitudinal studies: development and validation. J Chronic Dis 1987;40:373-83.

21. Brown LD, Cai TT, DasGupta A. Interval estimation for a binomia proportion. Stat Sci 2001;16:101-33.

22. Kroenke K, Lawrence VA, Theroux JF, et al. Postoperative complications after thoracic and major abdominal surgery in patients with and without obstructive lung disease. Chest 1993;104:1445-51.

23. Hansen JG, Pedersen L, Overvad K, et al. The prevalence of chronic obstructive pulmonary disease among Danes aged 45-84 years: population-based study. COPD 2008:5:347-52.

24. Mitchell E, Macdonald S, Campbell NC, et al. Influences on pre-hospital delay in the diagnosis of colorectal cancer: a systematic review. Br J Cancer 2008:98:60-70.

25. Storm HH, Engholm G, Hakulinen T, et al. Survival of patients diagnosed with cancer in the Nordic countries up to 1999-2003 followed to the end of 2006. A critical overview of the results. Acta Oncol 2010;49:532-44.

26. Thomsen RW, Lange $\mathrm{P}$, Hellquist $\mathrm{B}$, et al. Validity and underrecording of diagnosis of COPD in the Danish National Patient Registry. Respir Med 2011;105:1063-8.

27. Blichert-Hansen L, Nielsson MS, Nielsen RB, et al. Validity of the coding for intensive care admission, mechanical ventilation, and acute dialysis in the Danish National Patient Registry: a short report. Clin Epidemiol 2013;5:9-12.

28. Thygesen SK, Christiansen CF, Christensen S, et al. The predictive value of ICD-10 diagnostic coding used to assess Charlson comorbidity index conditions in the population-based Danish National Registry of Patients. BMC Med Res Methodol 2011;11:83

29. Hines RB, Chatla C, Bumpers HL, et al. Predictive capacity of three comorbidity indices in estimating mortality after surgery for colon cancer. J Clin Oncol 2009;27:4339-45. 